\title{
Conquering maternal mortality: skill development in medical curriculum
}

\author{
Parimala A, Nidhi Sharma*, K. Jayashree
}

Department of Obstetrics and Gynaecology, Saveetha Medical College, Saveetha Institute of Medical and Technical Sciences, Chennai, Tamil Nadu, India

Received: 14 December 2015

Revised: 22 January 2016

Accepted: 23 January 2016

\section{*Correspondence:}

Dr. Nidhi Sharma,

E-mail: drbonuramkumar@yahoo.co.in

Copyright: ( $)$ the author(s), publisher and licensee Medip Academy. This is an open-access article distributed under the terms of the Creative Commons Attribution Non-Commercial License, which permits unrestricted non-commercial use, distribution, and reproduction in any medium, provided the original work is properly cited.

\section{ABSTRACT}

Background: Maternal Mortality Rate remains to be high in developing countries despite the advances made in the modern world. A medical student needs to understand the basic clinical subjects and in a short span of one year translate it into patient care. A skill development method was initiated in the final year curriculum of medical students to integrate the basic knowledge of labor with the final outcome of reducing maternal mortality rate.

Methods: The skills were demonstrated on mannequins and simulation models of difficult situations in labour were provided. The study was conducted in Saveetha Medical College in the Department of Obstetrics and Gynaecology in May 2015 as a one day hands on workshop for medical undergraduate students. One hundred and fourteen medical students conducted normal labor, applied forceps and ventouse, sutured episiotomies and perineal tear and performed a drill on active management of third stage of labor on training mannequins. All the basic didactic teaching and its translation into clinical skills were tested pertaining to the problem of parturition. Plenary discussion of each demonstrable skill was done by a galaxy of experts. This was followed with Mind Mapping of concepts developed. Pretest and posttest helped the teaching faculty to assess the impact of knowledge generated. Feedback was obtained to improvise the existing teaching method and develop new teaching tools.

Results: The students were able to comprehend Conduct of Labor from its basics and decide on the relevant clinical implications. The case based skill demonstrations done on instrumental delivery, episiotomy suturing, clinical pelvimetry, active management of third stage of labor and monitoring of labor using partogram gave students hands on experience and improved their practical knowledge.

Conclusion: Skill Development in conduct of labour helps medical students to understand the clinical implications better. A well trained medical student can thus help to reduce maternal mortality rate in developing countries

Keywords: Skill development, Teaching tool, Conduct of labor, Maternal mortality, Medical Curriculum

\section{INTRODUCTION}

Maternal mortality rate is defined as the number of maternal deaths from direct or indirect obstetrical causes in a given period per 1,00,000 women of reproductive age group (15 - 49 years) during the same period. The term Maternal Mortality Ratio, MMR, refers to the number of maternal deaths in a given period per $1,00,000$ live births. The denominator is live birth though the maternal death can happen due to abortions or ectopic pregnancies. The number of abortions is difficult to calculate hence the denominator used is live birth. ${ }^{1}$ An estimated 289,000 women died in 2013 due to complications of pregnancy and child birth as compared to 523,000 in $1990 .^{2}$ The New United Nations Published data in May 2014 shows a $45 \%$ decline in maternal deaths since $1990 .^{3}$ Reduction of maternal mortality by 
$75 \%$ from 1990 to 2015 is specifically "Improving Maternal Health "part of the Goal 5 of the "Millennium Development Goals". Less than $1 \%$ of maternal deaths occur in developed world. The developing countries need to develop strategies to improve maternal mortality rate. It is usually not possible to predict which mother will develop complications so the high risk approach does not help much. More than $50 \%$ of pregnant women in developing countries are not given skilled attention of any sort from medical or paramedical personnel. ${ }^{3}$ Well trained doctors, nurses and midwives can provide efficient antenatal and intranatal care. Hence this study was conducted to enable medical students handle obstetrical emergencies and thereby reduce maternal mortality.

\section{METHODS}

The study was conducted in Saveetha Medical College in the Department of Obstetrics and Gynaecology in May 2015 as a one day hands on workshop for medical undergraduate students. The skills were demonstrated by experts to one hundred and fourteen medical students who were divided in five small groups. The groups took turns to attend the five stations. The moulage on mannequins and case based simulation models of difficult situations in labour were provided on five stations . The stations were as follows:

- Station 1: Instrumental delivery with forceps and ventouse

- Station 2: Suturing of episiotomy and perineal tears

- Station 3: Clinical pelvimetry and study of fetal skull

- Station 4: Active management of third stage of labor

- Station 5: Conduct of Second stage of labor

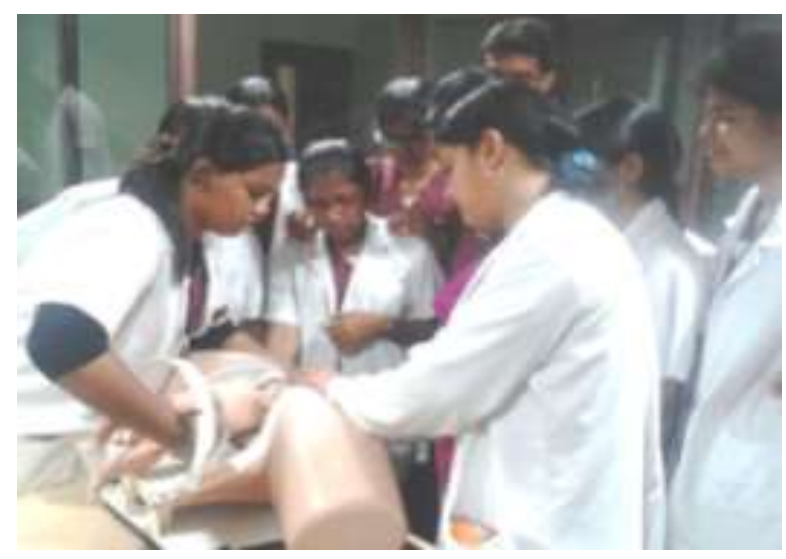

Figure 1 (a)

The medical students attended all stations in small groups. Plenary discussion of each demonstrable skill was done by a galaxy of experts (Figure 1). Each student conducted normal labour, applied forceps and ventouse, sutured episiotomy and perineal tear and performed active management of third stage of labour on training mannequins. All the clinical skills performed were scored with a pretest and post test. This was followed with Mind Mapping of concepts developed. Pretest and posttest helped the teaching faculty to assess the impact of knowledge generated. Feedback was obtained to improvise the existing teaching method and develop new teaching tools.

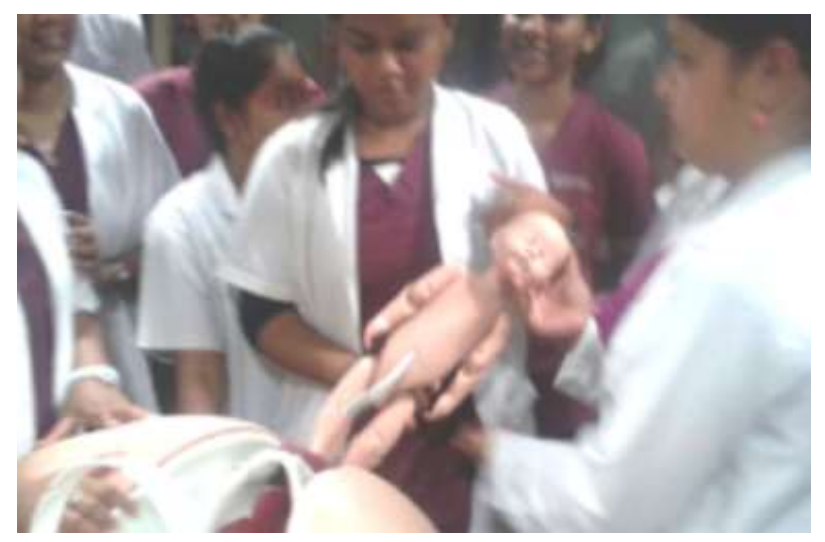

Figure 1 (b)

Figure 1 (a) and (b): Hands on simulation acts as a bridge between class room teaching and real clinical situations.

\section{Observations}

At each station a set of ten questions were used as a pretest for skill assessment. The pretest and post test questions were similar. The same procedure performance assessment tool was used to assess after the plenary discussion and procedure was over. The scores obtained were plotted using Box charts for pretest and posttest. The median, the $25^{\text {th }}$ percentile, the $75^{\text {th }}$ percentile and the maximum and minimum scores values in pretest and post test group were plotted using sigma plot (Figure 2).

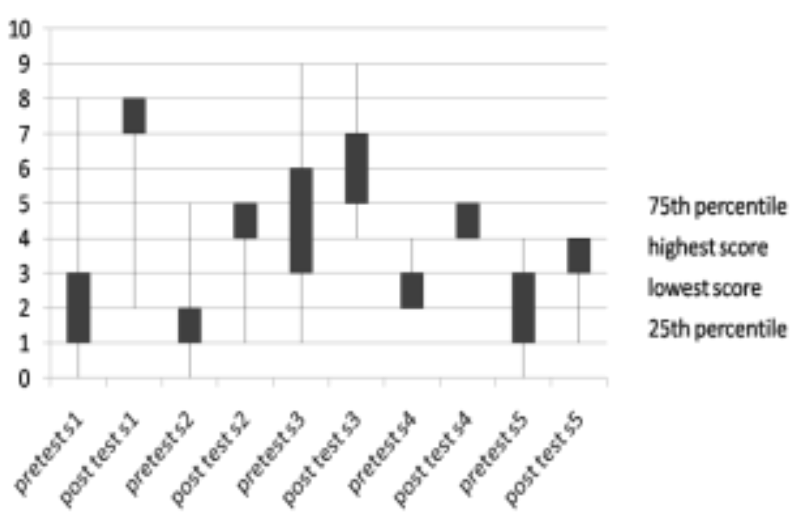

Figure 2: The median, the 25 th percentile, the 75 th percentile and the maximum and minimum scores values in pretest and post test group were plotted using Sigma plot. 


\section{Case based discussion}

Five scenarios of difficult situations in labour were given for problem solving to the medical students .Case Based Learning was done on mannequins. The students demonstrated the procedure of clinical pelvimetry, conduct of normal labour, forceps and vacuum extraction, suturing of perineal tears and episiotomy, active management of third stage of labour.

\section{Plenary session}

The experts highlighted that the forceps applied in severe anaemia is therapeutic and not prophylactic as the mother is already in distress. Propped up position and Oxygen inhalation is mandatory during labour in severe anaemia in pregnancy .Severe anaemia in any trimester requires blood transfusion .Parenteral Iron sucrose is a useful drug in moderate anemia. Active Management of Third stage of Labour can prevent post partum haemorrhage. Injectable antibiotics use can treat puerperal sepsis with anaemia.

\section{Mind mapping}

The medical students of each group charted the concepts gained collectively. This was a participatory activity, as the students of each group took one chart paper to outline their ideas. They signed their names below each chart. They were able to demonstrate procedures and clinical knowledge with only a very little help. It was also found that participation increased concept comprehension. ${ }^{7,8}$

\section{RESULTS}

A firm foundation of procedures was established with the help of birthing mannequins. The students were able to comprehend Conduct of Labour from its basics and decide on the relevant clinical implications. ${ }^{4-6}$ The case based skill demonstrations done on instrumental delivery, episiotomy suturing, clinical pelvimetry, active management of third stage of labour and monitoring of labour using partogram gave students hands on experience and improved their practical knowledge. There was a significant improvement in post test scores (Figure 2).

\section{DISCUSSION}

A thorough knowledge of basic sciences is essential for skill development. ${ }^{9-12}$ Thirty three women are dying every hour globally due to causes related to child birth ${ }^{13}$ A six hour hands on skill development on mannequins is definitely required in undergraduate medical curriculum. The teaching exercise was performed as an endeavour to train medical professions on mannequins and thereby equip them for handling obstetrical emergencies.

\section{CONCLUSIONS}

"Where tireless striving stretches its arms towards perfection. Into that heaven of freedom, let my country awake"- Rabindra Nath Tagore. In developing countries too we can reduce maternal mortality. Participatory learning activities keep students alert and interested. Skill Development in conduct of labor helps medical students to understand the clinical implications better. A well trained medical student can thus help to reduce maternal mortality rate in developing countries. The safe conduct of labor is a skill; let us protect it from dying.

\section{Competing interests}

We do not have any commercial association that might pose a conflict of interest in connection with the manuscript. We certify that neither this manuscript nor one with substantially similar content under our authorship has been published or is being considered for publication elsewhere.

\section{ACKNOWLEDGEMENTS}

We acknowledge the work of Dr. Mythilli Bhaskaran. Her work in designing the medical education curriculum inspired us. With the help of her work we were able to decide a protocol of integration of basic science departments to clinical departments in our university. A skill development laboratory has been established and integrated in medical curriculum due to her efforts.

We also acknowledge the work of OGSSI (Obstetrics and Gynaecology society of South India) in reducing the maternal mortality rate in the state of Tamil Nadu. The Maternal mortality Rate in Tamil Nadu in 2008 was 178 and has dropped to 134 in 2012.

Funding: No funding sources Conflict of interest: None declared

Ethical approval: The study was approved by the Institutional Ethics Committee

\section{REFERENCES}

1. Mudaliar AL, Menon MK. Maternal mortality .In: Mudaliar and Menon's Clinical Obstetrics .Eleventh Ed. Delhi. Universities Press (India) Private Limited. 2011.441-6.

2. LaleSay, Chou D, Gemmill A, Tuncalp O, Ann-Beth Moller, Daniels J. Global causes of maternal death : A WHO systematic analysis. The Lancet. 20142(6):323-34.

3. Trends in Maternal Mortality. Estimates by WHO, UNICEF, UNFPA, The World Bank and the United Nations Population Division. 1990 to 2013. Available at www.who.int

4. Fernandez R, Parker D, Kalus JS, Miller D, Pharm $\mathrm{D}$, Compton S. Using a human patient simulation mannequin to teach interdisciplinary Team Skills to 
pharmacy students. Am J Pharm Educ. 2007;71(3):51.

5. Gordon JA, Wilkerson WM, Shaffer DW, Armstong EG. "Practicing" Medicine without risk: Students and educators responses to high fidelity patient simulation, Medicineacademic, Educating physicians research reports. 2011;76(5):469-72,

6. Okuda Y, Bryson EO, DeMaria S, Jacobson L, Quinones J, Shen B, et al. The Utility of Simulation in Medical Education: What Is the Evidence? Mt Sinai J Med. 2009;76:330-43.

7. MacDowall j. The assessment and treatment of the acutely ill patient - the role of the patient simulator as a teaching tool in the undergraduate programme, Medical Teacher. 2006;28(4):326-9.

8. Schoening AM, Barbara SJ, Martha TJ. Simulated clinical experience. Nursing students perceptions and the educators' role, Nurse educator. 2006;31(6):2538.

9. Maruo T. Undergraduate and post graduate education clinical education in Kobe University of Medicine. Kobe J Med Sci.,1997;43(6):237-42.
10. Margolis CZ, Deckelbaum RJ, Henkin Y, Baram S, Cooper P, Alkan ML. A medical school for international health run by international partners. Acad Med. 2004;79(8):744-51.

11. Wijnen-Meijer M, Cate OT, Rademakers JJ, Van Der Schaaf M, Borleffs JC. The Influence of a vertically integrated curriculum on the transition to postgraduate training. Med Teach. 2009;31(11):e528-32.

12. Wijnen-Meijer $M$, ten Cate $O$, van der Schaaf $M$, Harendza S. Graduates from vertically integrated curricula. Clin Teach. 2013;10(3):155-9.

13. United Nations 2015 Millennium Development Goals Report. 2015. Available from http://www.un.org/millenniumgoals/reports.shtml. Assessed 1 December 2015.

Cite this article as: Parimala A, Sharma N, Jayashree K. Conquering maternal mortality: skill development in medical curriculum. Int J Reprod Contracept Obstet Gynecol 2016;5:441-4. 